\title{
Green infrastructure policy for sustainable urban development
}

\begin{abstract}
Green infrastructure refers to the network of natural and semi-natural areas, features and spaces in rural and urban areas, terrestrial, freshwater, coastal and marine areas. Green infrastructure can be strengthened through strategic and coordinated initiatives that focus on monitoring, restoring, improving and connecting existing areas and features as well as creating new uses and features. The principal issue that stimulates this work is to observe how planning policies could contribute towards achievement of sustainable urban development in Malaysian urban centres using GI attributes. The procedure involved for conducting this work was qualitative content analysis of planning policies that guides physical development of Peninsular Malaysia. The analysis conducted revealed the comprehensiveness of the GI. The policies give more emphasis on protection of natural areas, followed by conservation of Malaysian environment and provision of urban green spaces. The provision of urban trail was not provided anywhere in the policies analysed.
\end{abstract}

Keyword: Green infrastructure; Sustainable development; Urban development; Sustainability; Malaysia; Planning policy; Content analysis; Environmental protection; Natural areas; Urban trails; Green corridors; Nature conservation; Open space; Cities 